\title{
Ovarian Torsion: Sonographic Evaluation
}

\author{
Mark A. Helvie, MD,* and Terry M. Silver, $M D \dagger$
}

\begin{abstract}
The sonographic and clinical findings of 13 patients with surgically proven ovarian torsion are reported. Sonography demonstrated an abnormal pelvic mass in all patients. The appearance was nonspecific, ranging from solid to cystic, but frequently reflected the commonly associated ovarian pathology present in $69 \%$ of patients. The mass was large (mean diameter: $8 \mathrm{~cm}$ ) and frequently midline $(8 / 13)$. The clinical findings were variable and nonspecific, leading to a correct preoperative differential diagnosis in only $35 \%$ of patients. Preoperative sonography reduced the likelihood of unnecessary appendectomy in patients with ovarian torsion. Indexing Words: Ovarian torsion - Adnexal torsion - Fallopian tube - Ultrasonography
\end{abstract}

Ovarian torsion is an uncommon but important cause of lower abdominal pain in women and girls. Although rarely fatal, early recognition of this condition can lead to prompt operative intervention with gonadal salvage. There is a paucity of literature on sonography of ovarian torsion and it mostly consists of case reports. ${ }^{1-3}$ Furthermore, the only two previous "series" on this subject gave conflicting results. ${ }^{4,5}$ Thus, we reviewed our experience to determine the sonographic and clinical findings of surgically documented ovarian torsion.

\section{MATERIALS AND METHODS}

The clinical records of 26 patients with surgically documented ovarian torsion were retrospectively analyzed. Thirteen of these patients had preoperative transabdominal sonography. The patients ranged in age from 9 years to 56 years with a mean of 31 years and a median of 22 years. The sonograms were analyzed for the presence of a mass, cul-de-sac fluid, and associated uterine/adnexal findings. If a pelvic mass was present, its size, location, and sonographic character were recorded.

From the University of Michigan Medical Center, Department of Radiology, *Taubman Center and †Universidy Hospital, Ann Arbor, Michigan. For reprints contact Mark A. Helvie, MD, University of Michigan Medical Center, Department of Radiology, Taubman Center 2910/0326, 1500 East Medical Center Drive, Ann Arbor, Michigan 48109-0326.

\section{RESULTS}

Sonography demonstrated an abnormal pelvic/ adnexal mass related to the ovary and/or fallopian tubes in all patients studied. The mass ranged in size from $4 \mathrm{~cm}$ to $10 \mathrm{~cm}$ in largest dimension with a mean of $8 \mathrm{~cm}$. The mass assumed a midline location in $8 / 13(69 \%)$ patients, either in the pelvis or cephalad to the uterus. Cul-desac fluid was demonstrated in $1(8 \%)$ patient. The sonographic characteristics of the mass ranged from solid (Figure 1) to cystic (Figure 2): $5 / 13(38 \%)$ masses were primarily cystic, $4 / 13$ $(31 \%)$ were primarily solid, and thus $9 / 13(69 \%)$ had at least some cystic component. Only 1 patient demonstrated multiple, small, peripherally located ovarian cysts (Figure 3).

Underlying ovarian or adnexal pathology, in addition to the changes of torsion itself, was discovered in $9 / 13(69 \%)$ cases. Of these, $4(31 \%)$ had coexistent ovarian neoplasms ( 2 benign and 2 malignant), 2/13 (15\%) had chronic inflammatory change of fallopian tubes, $2 / 13(15 \%)$ had ovarian cysts, and 1/13 (8\%) had polycystic ovarian disease. The sonographic findings frequently reflected these different underlying pathological conditions (Table 1). The 13 patients that did not undergo preoperative sonography were also noted at operation to have frequently associated ovarian pathology in $8 / 13(62 \%)$ cases.

Because of the nonspecific sonographic findings, we evaluated the clinical presentation of all 26 patients. Twenty-five (96\%) patients had pelvic or abdominal pain, 18/25 (72\%) nausea and/ or vomiting, and 13/25 (52\%) leukocytosis. Al- 

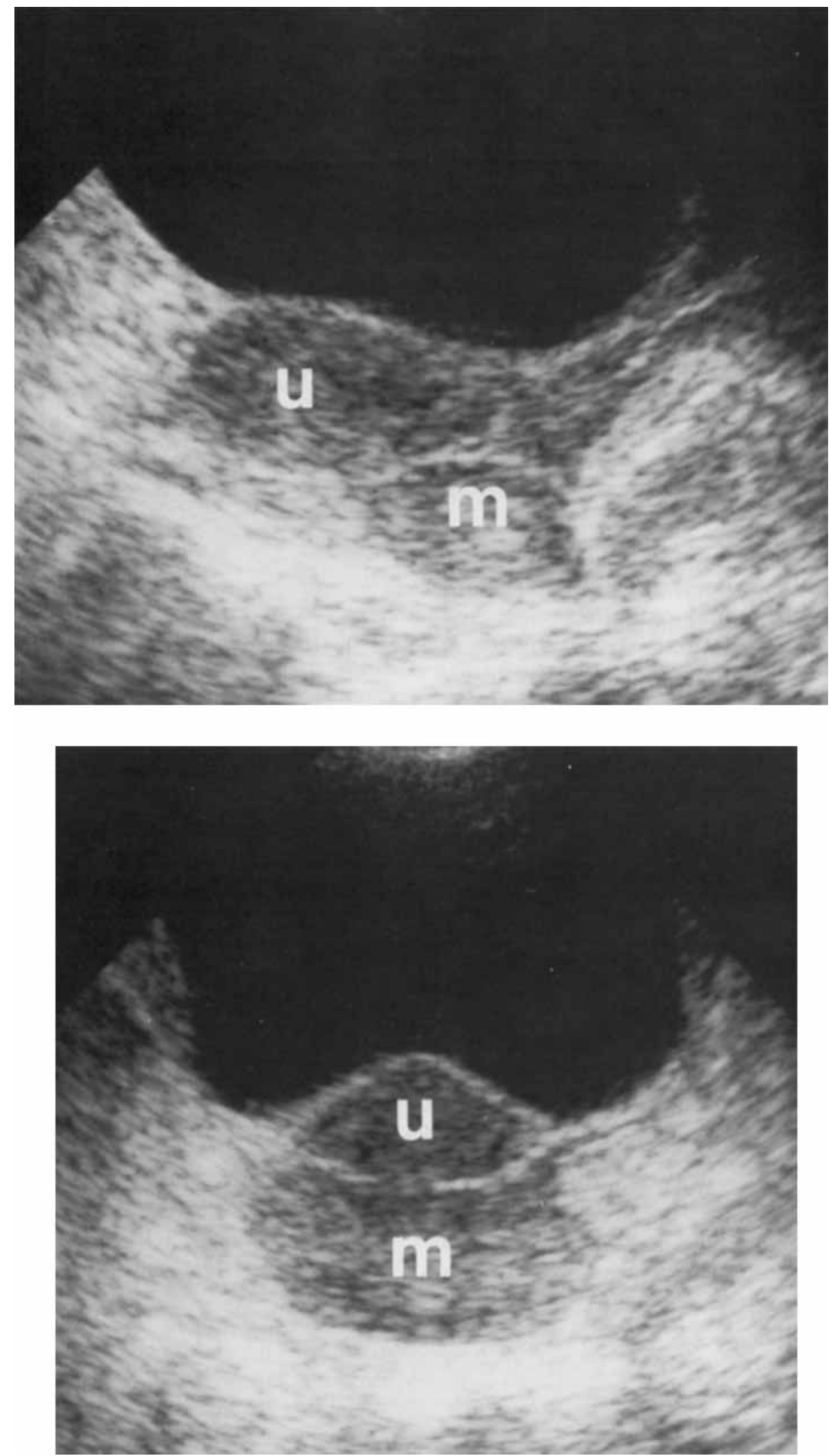

FIGURE 1 Case 7. Sagittal (A) and transverse (B) scans show a solid echogenic mass $(\mathrm{m})$ posterior to the uterus $(u)$ in the posterior cul-de-sac. Pathologic examination revealed ovarian hemorrhagic necrosis. 


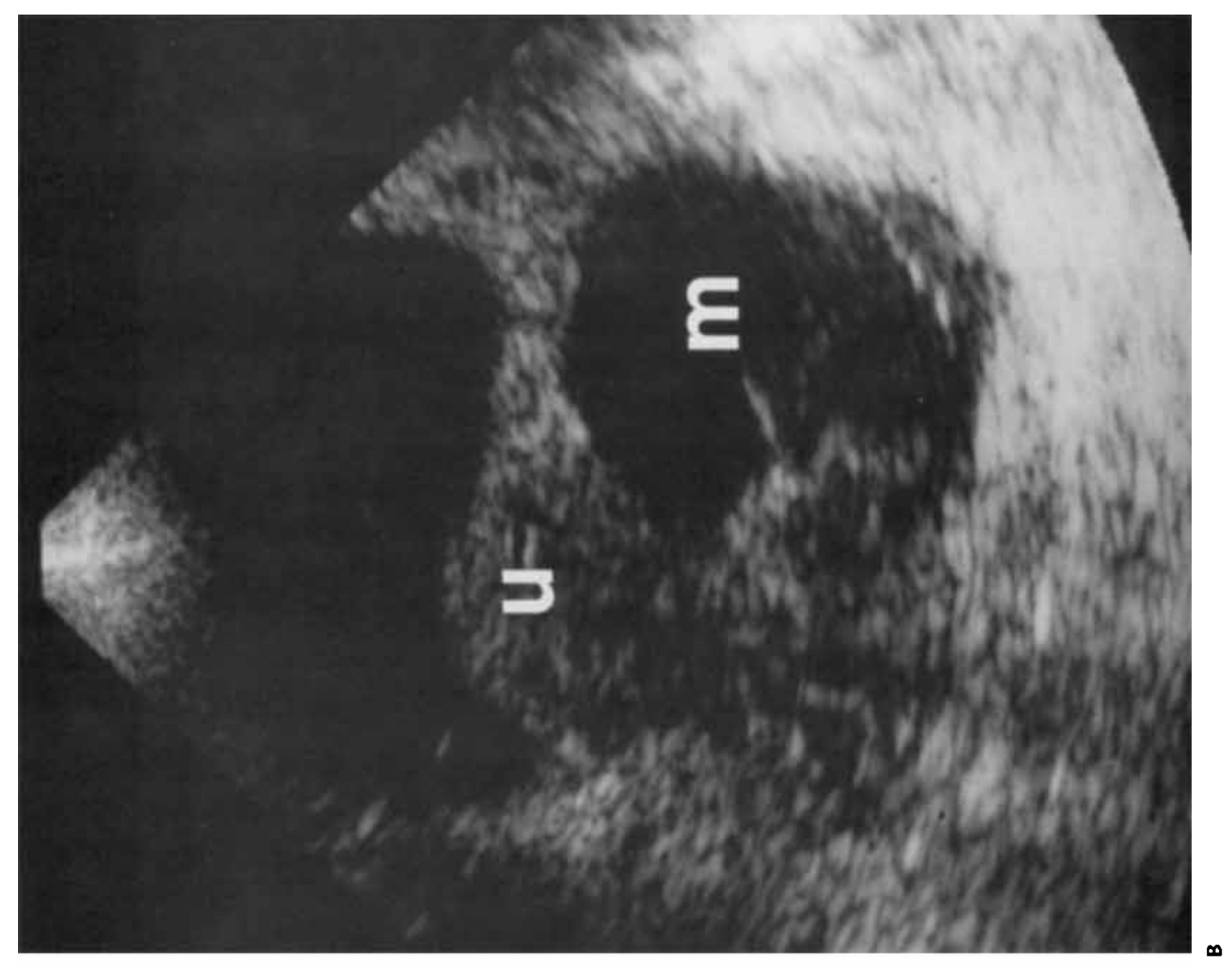

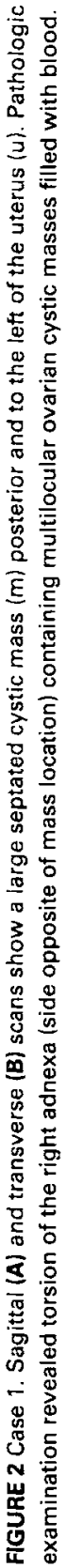

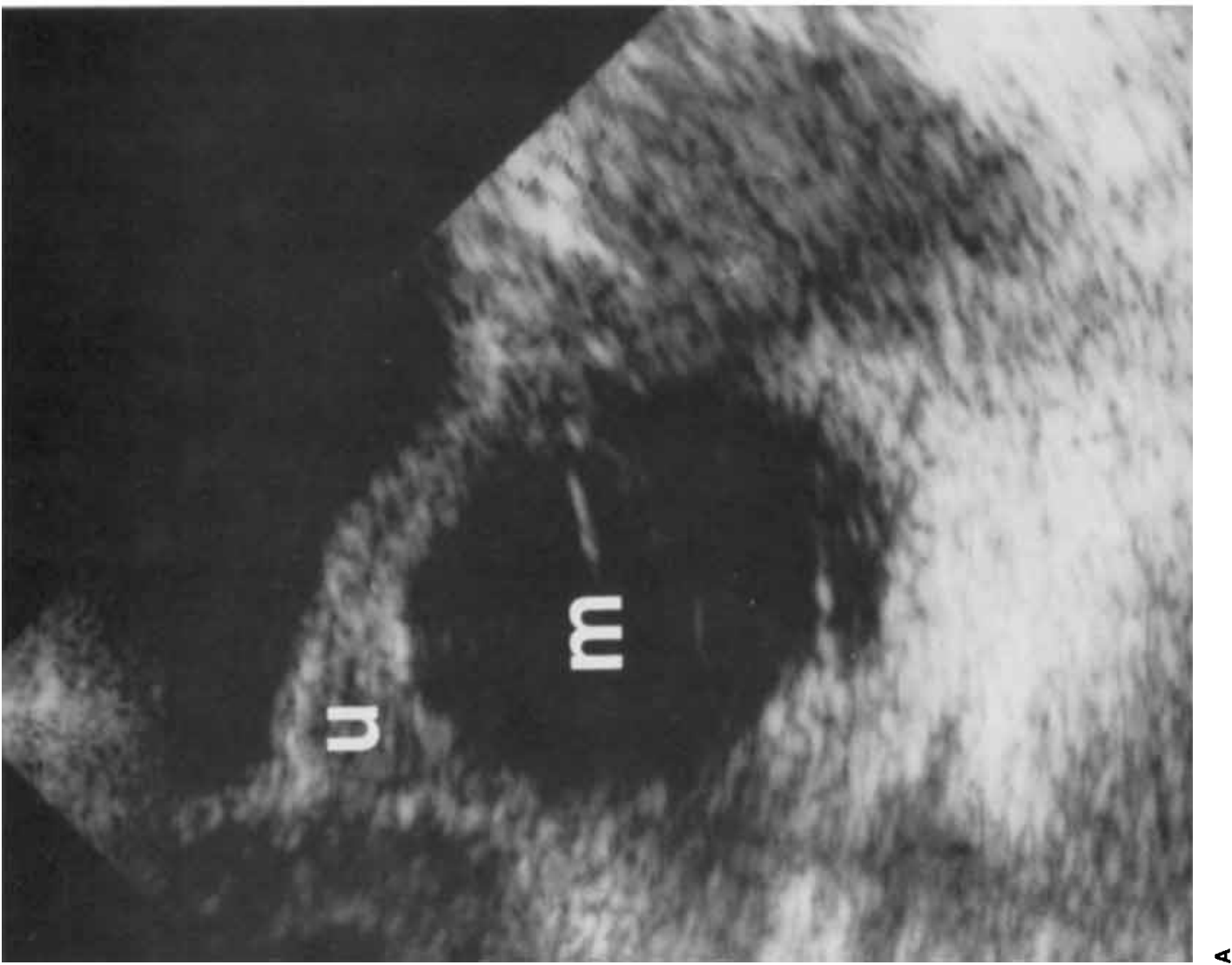



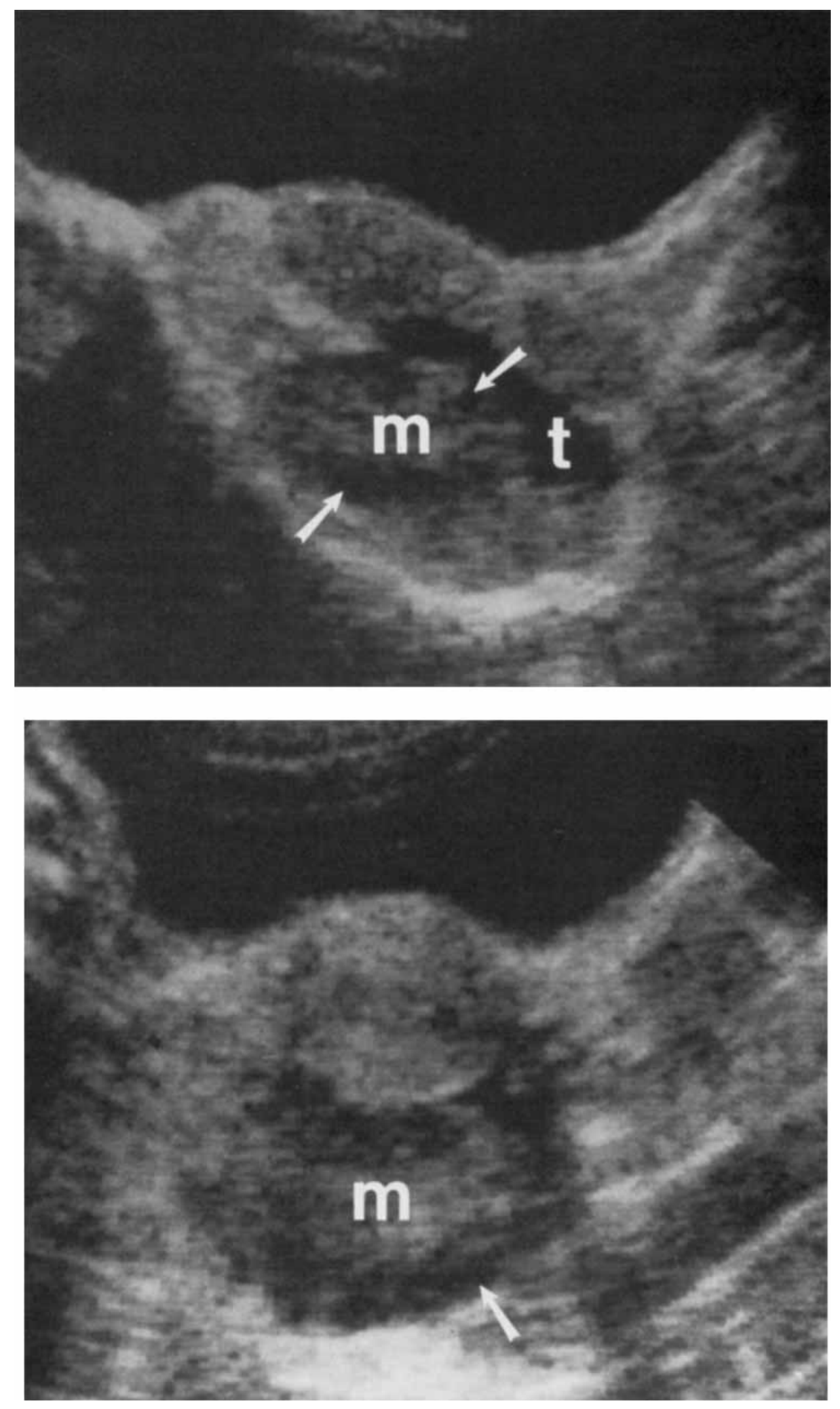

FIGURE 3 Case 11. Sagittal (A) and transverse (B) scans show retra-uterine solid mass $(\mathrm{m})$ with peripherally located hypoechoic structures, probably cysts (arrows). Additionally, a tubular hypoechoic structure (t) anterior and to the left of the mass is shown. Pathologic examination revealed infarction of both the right ovary and fallopian tube. 
TABLE 1

Sonographic and Pathologic Features of Adnexal Torsion

\begin{tabular}{|c|c|c|c|}
\hline Case & $\begin{array}{c}\text { Adnexal Mass, } \\
\text { Greatest } \\
\text { Dimension }\end{array}$ & $\begin{array}{l}\text { Sonographic } \\
\text { Features }\end{array}$ & Adnexal Pathology \\
\hline & $\mathrm{cm}$ & & \\
\hline 1 & 7 & Cystic mass, septations & $\begin{array}{l}\text { Ovarian hemorrhage, blood } \\
\text { filled ovarian cysts }\end{array}$ \\
\hline 2 & 10 & Cystic mass & Papillary-serous tumor \\
\hline 3 & 10 & Cystic mass, septations & $\begin{array}{l}\text { Chronic salpingitis, } \\
\text { hematosalpinx, ovarian } \\
\text { necrosis }\end{array}$ \\
\hline 4 & 4.5 & Solid mass & $\begin{array}{l}\text { Polycystic ovarian disease, } \\
\text { ovarian infarction }\end{array}$ \\
\hline 5 & 10 & Cystic mass & Cystic teratoma \\
\hline 6 & 10 & Cystic mass, septations & $\begin{array}{l}\text { Primary endometroid cancer of } \\
\text { ovary }\end{array}$ \\
\hline 7 & 5.5 & Solid, echogenic mass & Ovarian hemorrhagic necrosis \\
\hline 8 & 6 & $\begin{array}{l}\text { Solid, small single cystic } \\
\text { component }\end{array}$ & Ovarian hemorrhagic infarction \\
\hline 9 & 10 & $\begin{array}{l}\text { Heterogeneous cystic and } \\
\text { solid components }\end{array}$ & $\begin{array}{l}\text { Hydrosalpinx with chronic } \\
\text { inflammation, omental cake }\end{array}$ \\
\hline 10 & 4 & $\begin{array}{l}\text { Solid/questionable small } \\
\text { cystic component }\end{array}$ & $\begin{array}{l}\text { Ovarian edema and } \\
\text { hemorrhage }\end{array}$ \\
\hline 11 & 7 & Solid with peripheral cysts & Ovarian infarction \\
\hline 12 & 9 & $\begin{array}{l}\text { Solid, echogenic, acoustic } \\
\text { shadowing }\end{array}$ & Infarcted dermoid cyst \\
\hline 13 & 6 & Solid & $\begin{array}{l}\text { Thick walled }(1 \mathrm{~cm}) \text { ovarian cyst } \\
\text { containing clotted blood }\end{array}$ \\
\hline
\end{tabular}

though commonly thought to represent a rather acute event, ${ }^{4}$ the average duration of symptoms prior to diagnosis was 2.8 days, with a median of 2 days. A pelvic mass was clinically detected in $14 / 26(54 \%)$ patients either by abdominal or pelvic examination. The clinical difficulty in diagnosing this condition was manifest by the fact that only $9 / 26(35 \%)$ patients had ovarian/adnexal torsion included in the preoperative clinical differential diagnosis. Interestingly, no patient with preoperative sonography underwent appendectomy while $4 / 13(31 \%)$ patients operated upon without preoperative sonography underwent appendectomy of a normal appendix. Right-sided ovarian torsion was again noted to predominate, ${ }^{4,6}$ occurring in $18 / 26(69 \%)$ patients.

\section{DISCUSSION}

Torsion of the adnexa is an uncommon gynecological disorder caused by rotation of the ovary or adnexa about the ovarian pedicle resulting in arterial, venous, or lymphatic obstruction. Partial obstruction may lead to a condition known as massive ovarian edema, ${ }^{3,8}$ which is associated with huge ovaries. More commonly, persistent torsion eventually leads to ischemia and ovarian infarction. Ovarian torsion occurs primarily in young women ${ }^{9}$ but can occur in children..$^{1,10,11}$ It is frequently associated with ovarian masses, $, 4,6,9$ which are felt to potentiate torsion. ${ }^{2,4,10}$ The condition remains a diagnostic dilemma largely because of the nonspecific clinical, laboratory, and imaging findings, ${ }^{1,3,4,9}$ associated with the need for early operative intervention in order to achieve gonadal salvage prior to the time of ovarian infarction.

The sonographic findings of ovarian torsion in this study were frequently related to the associated ovarian condition. In those patients without preexisting or associated ovarian pathology, the most common sonographic finding was of a relatively echogenic ovarian mass containing some cystic component. The echogenic appearance is thought to relate to ovarian edema and possibly hemorrhage. ${ }^{1,3,4}$ However, the sonographic appearance of multiple peripherally located ovarian cysts, was demonstrated in only 1 of our patients. Although we were unable to confirm this previously reported finding considered relatively specific for ovarian torsion, especially in the prepubertal group, ${ }^{5}$ only 1 of our patients was prepubertal (Case 5). We also observed fewer patients with cul-de-sac fluid than previous reports $(8 \%$ versus $32 \%))^{5}$ The reason for this difference is unknown.

There were no specific sonographic appearances associated with ovarian torsion in our group of patients as a whole. Nonetheless, sonog- 
raphy always demonstrated an abnormal pelvic adnexal mass that could be clinically palpated in just over half of the patients. The demonstration of a pelvic mass by sonography probably explains the marked difference in the number of appendectomies performed on patients without sonography when compared to those having undergone preoperative sonography. Since the clinical symptoms of these two disorders closely resemble each other, sonography can direct the surgeon toward the adnexa and away from the appendix. However, an appendiceal inflammatory mass cannot always be sonographically differentiated from an adnexal mass.

Although some previous reports ${ }^{4}$ indicate that ovarian torsion is an acute event, a subacute course was common (mean duration of symptoms was 2.8 days) and should not be used to argue against ovarian torsion in the differential diagnosis of an adnexal mass.

In summary, the sonographic findings of ovarian torsion are nonspecific, largely due to the variable appearance of the commonly associated ovarian pathology. However, the possibility of ovarian torsion should be considered when a midline pelvic mass is discovered in a young patient with acute or subacute lower abdominal pain with nausea and vomiting. The potential advantages of endovaginal scanning (improved resolution and patient comfort) remain to be validated in patients with ovarian torsion. If imagedirected Doppler evaluation of the ovarian vasculature proves feasible, ${ }^{12}$ this technique may represent a useful noninvasive method to diagnose this condition while gonadal salvage is still possible prior to ovarian infarction.

\section{REFERENCES}

1. Farrell T, Boal D, Teele R, et al: Acute torsion of normal uterine adnexa in children: Sonographic demonstration. AJR 139:1223-1225, 1982.

2. Bowen A: Ovarian torsion diagnosed by ultrasonography. Southern Med J 78:1376-1378, 1985.

3. Han B, Babcock D: Ultrasonography of torsion of normal uterine adnexa. J Ultrasound $M e d$ 2:321$323,1983$.

4. Warner M, Fleischer A, Edell S, et al: Uterine adnexal torsion: Sonographic findings. Radiology 154:773-775, 1985.

5. Graif M, Shalev J, Strauss S, et al: Torsion of the ovary: sonographic features. AJR 143:1331-1334, 1984.

6. Kelberg M, Randall J: Torsion of adnexal tumors and its relation to surgical emergency. Am J Obstet Gynecol 52:464-468, 1946.

7. Kalstone C, Jaffe $\mathrm{R}$, Abell $\mathrm{M}$ : Massive edema of the ovary simulating fibroma. Obstet Gynecol 34:564-571, 1969.

8. Alberda A, Wladimiroff J, Wielenga G, et al: Massive ovarian oedema. Br J Obstet Gynecol 88:569$573,1981$.

9. Lomano J, Trelford J, Ullery J: Torsion of the uterine adnexa causing an acute abdomen. Obstet Gynecol 35:221-225, 1970.

10. James D, Barber H, Graber E: Torsion of normal uterine adnexa in children. Obstet Gynecol 35:226-230, 1970.

11. Castelman B, McNeely B: Case records of the Massachusetts General Hospital, Case 9-1971. New Engl J Med 284:491-496, 1971.

12. Taylor K, Burns $P$, Woodcock J, et al: Blood flow in deep abdominal and pelvic vessels: Ultrasonic pulsed-Doppler analysis. Radiology 154:487-493, 1985. 